\title{
Gender Role in Irritable Bowel Syndrome: A Comparison of Irritable Bowel Syndrome Module (ROME III) Between Male and Female Patients
}

\author{
Sanam Javid Anbardan, ${ }^{1}$ Nasser Ebrahimi Daryani, ${ }^{1 *}$ Seyed-Mohammad Fereshtehnejad, ${ }^{2}$ Sahar Taba Taba Vakili, ${ }^{3}$ Mohammad \\ Reza Keramati ${ }^{4}$ and Hossein Ajdarkosh ${ }^{5}$ \\ ${ }^{1}$ Department of Gastroenterology and Hepatology, ${ }^{2}$ Gastrointestinal and Liver Disease Research Center (GILDRC), Firoozgar Clinical Research \\ Development Center, Tehran University of Medical Sciences, Tehran, Iran; ${ }^{3}$ Department of Internal Medicine, Shahid Beheshti University of \\ Medical Sciences, Tehran, Iran; ${ }^{4}$ Department of Surgery, Tehran University of Medical Sciences, Tehran, Iran; and ${ }^{5}$ Gastrointestinal \& Liver \\ Disease Research Center (GILDRC), Tehran University of Medical Sciences, Tehran, Iran
}

\section{Background/Aims}

Irritable bowel syndrome (IBS) is a widespread chronic health condition which is significantly more prevalent in women. We conducted a gender difference analysis by comparing findings of men and women to determine whether any significant differences exist or not.

\section{Methods}

This single-center study was conducted in Tehran, Iran during 2009-2010. IBS was diagnosed on the basis of Rome III criteria. A simple "10 point" objective questionnaire was used.

Results

A total number of 144 IBS patients including $44(30.6 \%)$ males and $100(69.4 \%)$ females with the mean age of $37.50 \pm$ 11.50 years, were assessed. The only differently observed symptom was nausea which was significantly more prevalent in females $(49 \%$ vs $18.2 \%, P<0.001)$. The commonest subtype of IBS in male patients was diarrhea predominant IBS $(38.6 \%)$; while, constipation predominant IBS was the most frequent type among females (38\%). Moreover, the frequency of loose, mushy or watery stools within the last 3 months was significantly higher among males $(2.11 \pm 1.67$ vs $1.37 \pm 1.50, P=$ 0.009).

\section{Conclusions}

We report that gender is important in IBS. Although qualitative comparison of different subtypes of IBS between male and female failed to meet the statistically significant level, the answers to the corresponding questions of ROME III IBS module suggest the higher prevalence of bowel movements and looser stool in males. Moreover, nausea was reported more often by females.

(J Neurogastroenterol Motil 2012;18:70-77)

Key Words

Gender identity; Irritable bowel syndrome; Questionnaire; ROME III

Received: July 14, 2011 Revised: September 4, 2011 Accepted: September 6, 2011

(c) This is an Open Access article distributed under the terms of the Creative Commons Attribution Non-Commercial License (http://creativecommons. org/licenses/by-nc/3.0) which permits unrestricted non-commercial use, distribution, and reproduction in any medium, provided the original work is properly cited.

*Correspondence: Nasser Ebrahimi Daryani, MD

Division of Gastroenterology, Department of Gastroenterology and Hepatology, Imam Khomeini Hospital, Tehran University of Medical Sciences, Tehran, Iran

Tel: +98-21-8879-9446, Fax: +98-21-8879-7611-9, E-mail: nasere@yahoo.com

Financial support: None.

Conflicts of interest: None. 


\section{Introduction}

Irritable bowel syndrome (IBS) is a widespread chronic health condition, characterized by a defined symptom complex in the absence of any biochemical or pathological structural abnormalities. The novelest symptom criteria are the Rome III criteria. ${ }^{1}$ Accordingly, criterion fulfilled for the last 3 months with symptoms begun at least 6 months prior to diagnosis, would make IBS diagnosis complete. IBS is classified as diarrhea-predominant, constipation predominant, or alternating based on the predominant bowel habit. ${ }^{2}$

In Asian countries, $1 \%$ to $10 \%$ of the population has symptoms compatible with IBS. ${ }^{3}$ Despite the high prevalence of IBS, the etiology of this condition remains unknown. A long-recognized characteristic of IBS is gender disparity, whereby female patients appear to outnumber male patients in a ratio of $2: 1{ }^{4}$ While the underlying mechanism for this disparity is not well understood, the observation of gender differences in functional bowel disorders extends beyond IBS as well.

The concept of gender role will be suggested as a possible contributing factor in the prevalence of IBS for both women and men. In general, women are more likely to complain of persistent, episodic or chronic visceral and musculo-skeletal pains. Women do report more multiple or recurrent pains than men. ${ }^{3-8}$

In examining the literature on gender differences in IBS, it is apparent that most of the research has not tested for these differences in a scientifically rigorous manner. ${ }^{9,10}$ Some studies on IBS enrolled only women in their samples, although some others did include men, and there was often no gender difference in the analysis performed beyond description of sample demographics. ${ }^{11-14}$

Moreover, most of the previous studies on gender-related differences in IBS symptoms were based on the previous versions of ROME criteria. ${ }^{15-17}$ To our knowledge few studies to date have examined this association according to the ROME III criteria. In this study, we conducted a gender difference analysis by comparing findings for men and women through statistical analyses to determine whether or not significant differences existed.

\section{Materials and Methods}

\section{Patient Enrollment}

This single-center study was conducted in a private Gastro- enterology Clinic in Tehran, Iran during 2009-2010. IBS was diagnosed on the basis of Rome III criteria, according to which, recurrent abdominal pain or discomfort at least 3 days per month in the last 3 months with onset of symptoms at least 6 months back was essential for suspecting IBS. In addition, to diagnose a person as IBS, the pain was needed to be associated with at least 2 out of 3 features which included improvement of pain or discomfort with defecation and onset of pain or discomfort associated with changes in frequency or form (appearance) of stool. Imaging studies including colonoscopy were also performed wherever the approved criteria were met (eg, presence of diarrhea and age $>50$ years). Furthermore, any cases with any organic disorders, inflammatory bowel disease, celiac disease, malabsorption disorders and gall bladder diseases were excluded from the study.

The study protocol was approved by the ethics committee of medical faculty, Tehran University of Medical Sciences (TUMS).

\section{Assessments}

Finally 144 patients were confirmed to have IBS and recruited to the study. A simple "10 point" objective questionnaire based on Rome III IBS module (Table 1) was used in this study. The English version of the official ROME III questionnaire was previously translated into the native language Persian. The validity and reliability of this translated questionnaire were formerly evaluated in another study on Iranian IBS patients which were shown to be valid and reliable, showing a value of above 0.7 for Cronbach alpha coefficient. ${ }^{18}$

Thereafter, the patients were further subclassified into diarrhea predominant IBS (IBS-D) if they had loose, mushy or water stools in the last 3 months with no hard or lumpy stools ([question $9=0$ ] and [question $10>0$ ]); constipation predominant IBS (IBS-C), if they had hard or lumpy stools with no loose, watery mushy or watery stools in the past 3 months ([question $9>$ $0]$ and [question $10=0])$; mixed IBS (IBS-M), if they had both loose and hard stools in the past 3 months ([question $9>$ $0]$ and [question $10>0$ ]); and unsubtyped IBS (IBS-U), if they did not report either loose or hard stools in the past 3 months ([question $9=0]$ and [question $10=0]$ ).

In addition to the IBS modules, baseline characteristics of the patients including sex, age, marital status, educational level, occupational category and history of smoking were recorded. Moreover, the data on their related symptoms consisted of reflux, nausea, vomiting, anorexia, weight loss, fatigue and heart burn were asked and added to the medical records of the IBS patients. It must be noted that the description for these symptoms was based 
Table 1. Irritable Bowel Syndrome Module According to ROME Criteria III (Modified from Longstreth et $\mathrm{al}^{1}$ )

\begin{tabular}{|c|c|}
\hline Question & Answer \\
\hline 1. In the last 3 months, how often did you have discomfort or pain anywhere in your abdomen? & $\begin{array}{l}0 \text { Never } \\
1 \text { Less than one day a month } \\
2 \text { One day a month } \\
3 \text { Two to three days a month } \\
4 \text { One day a week } \\
5 \text { More than one day a week } \\
6 \text { Every day }\end{array}$ \\
\hline $\begin{array}{l}\text { 2. For women: Did this discomfort or pain occur only during your menstrual } \\
\text { bleeding and not at other times? }\end{array}$ & $\begin{array}{l}0 \text { No } \\
1 \text { Yes } \\
2 \text { Does not apply because I have had the } \\
\text { change in life (menopause) or I am a male }\end{array}$ \\
\hline 3. Have you had this discomfort or pain 6 months or longer? & $\begin{array}{l}0 \text { No } \\
1 \text { Yes }\end{array}$ \\
\hline 4. How often did this discomfort or pain get better or stop after you had a bowel movement? & $\begin{array}{l}0 \text { Never or rarely } \\
1 \text { Sometimes } \\
2 \text { Often } \\
3 \text { Most of the time } \\
4 \text { Always }\end{array}$ \\
\hline 5. When this discomfort or pain started, did you have more frequent bowel movements? & $\begin{array}{l}0 \text { Never or rarely } \\
1 \text { Sometimes } \\
2 \text { Often } \\
3 \text { Most of the time } \\
4 \text { Always }\end{array}$ \\
\hline 6. When this discomfort or pain started, did you have less frequent bowel movements? & $\begin{array}{l}0 \text { Never or rarely } \\
1 \text { Sometimes } \\
2 \text { Often } \\
3 \text { Most of the time } \\
4 \text { Always }\end{array}$ \\
\hline 7. When this discomfort or pain started, were your stools (bowel movements) looser? & $\begin{array}{l}0 \text { Never or rarely } \\
1 \text { Sometimes } \\
2 \text { Often } \\
3 \text { Most of the time } \\
4 \text { Always }\end{array}$ \\
\hline 8. When this discomfort or pain started, how often did you have harder stools? & $\begin{array}{l}0 \text { Never or rarely } \\
1 \text { Sometimes } \\
2 \text { Often } \\
3 \text { Most of the time } \\
4 \text { Always }\end{array}$ \\
\hline 9. In the last 3 months, how often did you have hard or lumpy stools? & $\begin{array}{l}0 \text { Never or rarely } \\
1 \text { Sometimes } \\
2 \text { Often } \\
3 \text { Most of the time } \\
4 \text { Always }\end{array}$ \\
\hline 10. In the last 3 months, how often did you have loose, mushy or watery stools? & $\begin{array}{l}0 \text { Never or rarely } \\
1 \text { Sometimes } \\
2 \text { Often } \\
3 \text { Most of the time } \\
4 \text { Always }\end{array}$ \\
\hline
\end{tabular}


on the definitions recommended by ROME III criteria. ${ }^{1}$ More precisely, the definition used to describe nausea was termed as chronic idiopathic nausea in ROME III criteria as bothersome nausea, occurring at least several times per week in the last 3 months which was not usually associated with vomiting in the absence of abnormalities at upper endoscopy or metabolic disease that explains the nausea.

All of the recorded variables were compared between the 2 genders.

\section{Statistical Methods}

Data were expressed as mean \pm standard deviation for continuous and frequency percentage for nominal and categorical variables. Independent Sample T-test was used to compare the mean of continuous variables between males and females includ- ing baseline characteristics, the mean score for each of the 10 questions and total IBS module score. The comparison of qualitative variables between groups (such as subtypes of IBS) was performed by means of Chi-square test. The differences were considered statistically significant if the $P$-value was less than 0.05 (maximum type one error of 5\%) and all of the analytical procedures were performed by SPSS software version 16 (SPSS Inc., Chicago, IL, USA).

\section{Results}

\section{Baseline and Clinical Characteristics}

A total number of 144 IBS patients were recruited in this prospective study. They were consisted of 44 (30.6\%) males and

Table 2. Baseline and Clinical Characteristics of the Irritable Bowel Syndrome Patients Regarding Different Sex Groups

\begin{tabular}{|c|c|c|c|c|}
\hline \multirow{2}{*}{ Variable } & \multirow{2}{*}{ Total $(\mathrm{N}=144)$} & \multicolumn{2}{|c|}{ Sex groups } & \multirow{2}{*}{$P$-value } \\
\hline & & Male $(\mathrm{n}=44)$ & Female $(\mathrm{n}=100)$ & \\
\hline Age (mean $\pm \mathrm{SD}, \mathrm{yr})$ & $37.50 \pm 11.50$ & $37.91 \pm 11.45$ & $37.32 \pm 11.57$ & 0.778 \\
\hline $\mathrm{BMI}\left(\right.$ mean $\left.\pm \mathrm{SD}, \mathrm{kg} / \mathrm{m}^{2}\right)$ & $24.64 \pm 11.64$ & $26.59 \pm 19.68$ & $23.74 \pm 4.61$ & 0.195 \\
\hline \multicolumn{5}{|l|}{ Marital status (n $[\%])^{\mathrm{a}}$} \\
\hline Married & $107 / 141(75.9)$ & $30(68.2)$ & 77/97 (79.4) & 0.150 \\
\hline \multicolumn{5}{|l|}{ Educational status $(\mathrm{n}[\%])^{\mathrm{b}}$} \\
\hline Illiterate & $7 / 143(4.9)$ & $1(2.3)$ & $6 / 99(6.1)$ & 0.337 \\
\hline Primary and/or secondary school & $76 / 143(53.1)$ & $27(61.4)$ & $49 / 99(49.5)$ & \\
\hline College and/or university & $60 / 143(42)$ & $16(36.4)$ & $44 / 99(44.4)$ & \\
\hline \multicolumn{5}{|l|}{ Occupational status (n [\%]) } \\
\hline Housewife & $42(29.2)$ & 0 & $42(42)$ & $<0.001^{\mathrm{c}}$ \\
\hline Practitioner & $80(55.6)$ & $38(86.4)$ & $42(42)$ & \\
\hline Workless & $5(3.5)$ & $4(9.1)$ & $1(1)$ & \\
\hline Smoking (n [\%]) & $14(10)$ & $9(20.9)$ & $5(5)$ & $0.011^{\mathrm{c}}$ \\
\hline \multicolumn{5}{|l|}{ Symptoms (n [\%]) } \\
\hline Reflux & $49(34.3)$ & $13(29.5)$ & $36(36)$ & 0.428 \\
\hline Nausea & $57(39.6)$ & $8(18.2)$ & $49(49)$ & $<0.001^{\mathrm{c}}$ \\
\hline Vomiting & $18(12.5)$ & $3(6.8)$ & $15(15)$ & 0.273 \\
\hline Anorexia & $63(43.8)$ & $18(40.9)$ & $45(45)$ & 0.649 \\
\hline Weight loss & $48(33.3)$ & $16(36.4)$ & $32(32)$ & 0.609 \\
\hline Fatigue & $108(75)$ & $33(75)$ & $75(75)$ & 1.000 \\
\hline Heart burn & $51(35.7)$ & $13(29.5)$ & $38(38)$ & 0.309 \\
\hline \multicolumn{5}{|l|}{ Type of IBS (n [\%]) } \\
\hline IBS-C (constipation) & $52(36.1)$ & $14(31.8)$ & $38(38)$ & \\
\hline IBS-D (diarrhea) & $49(34)$ & $17(38.6)$ & $32(32)$ & 0.550 \\
\hline
\end{tabular}

${ }^{\mathrm{a}}$ Missing $=3$ (female), ${ }^{\mathrm{b}}$ Missing $=1$ (female), ${ }^{\mathrm{c}}$ Statistically significant difference.

IBS, irritable bowel syndrome. 


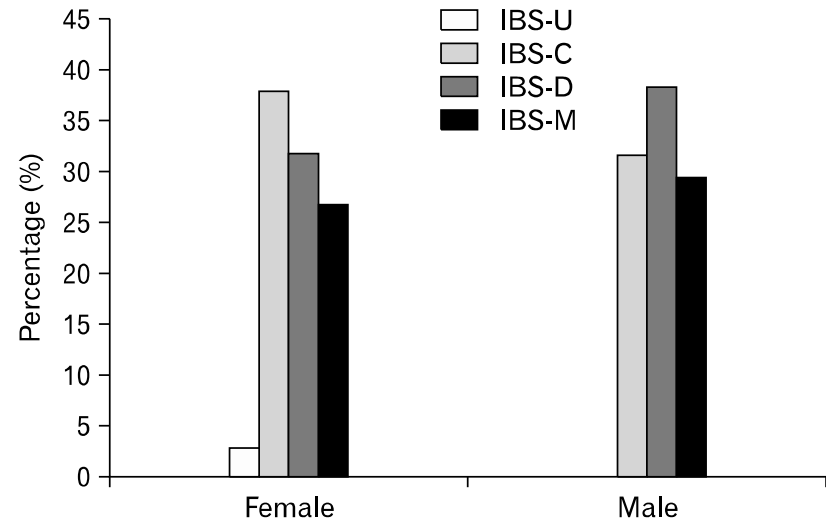

Figure 1. Distribution of different types of irritable bowel syndrome in female and male patients. IBS, irritable bowel syndrome; IBS-U, unsubtyped IBS; IBS-C; constipation predominant IBS; IBS-D, diarrhea predominant IBS; IBS-M, mixed IBS.

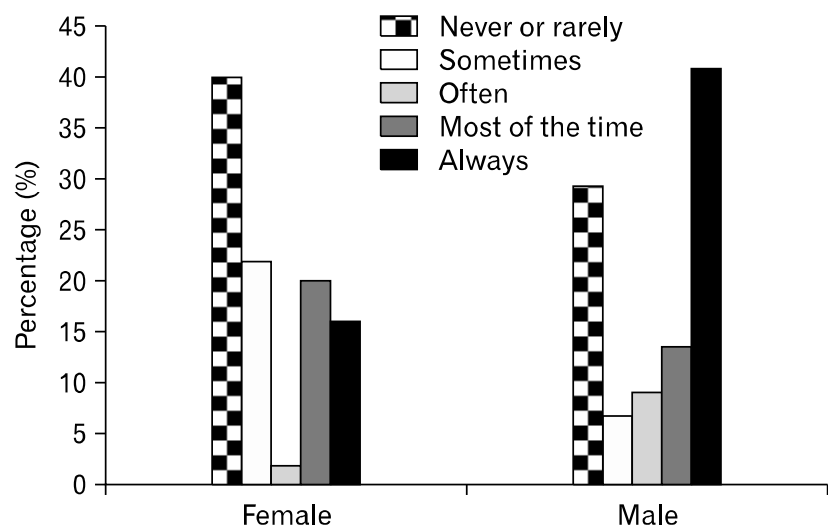

Figure 3. Distribution of different severity of more frequent looser stools after the start of discomfort or pain in female and male irritable bowel syndrome patients $(P=0.002)$.

$100(69.4 \%)$ females with the mean age of $37.50 \pm 11.50$ years. Baseline and clinical characteristics of the patients regarding their gender group are shown in Table 2. The mean age of the patients was not significantly different between males and females (37.91 \pm 11.45 years vs $37.32 \pm 11.57$ years, $P=0.778$ ). Among baseline characteristics, occupational status and smoking prevalence were significantly different between 2 genders $(<0.001$ and 0.011 , respectively). Moreover, the only differently observed symptom was nausea which was significantly more prevalent in females $(18.2 \%$ vs $49.0 \%, P<0.001)$.

\section{Irritable Bowel Syndrome Module}

The most common types of IBS were IBS-C (36.1\%) and IBS-D (34\%) forms, respectively. As shown in Figure 1, the

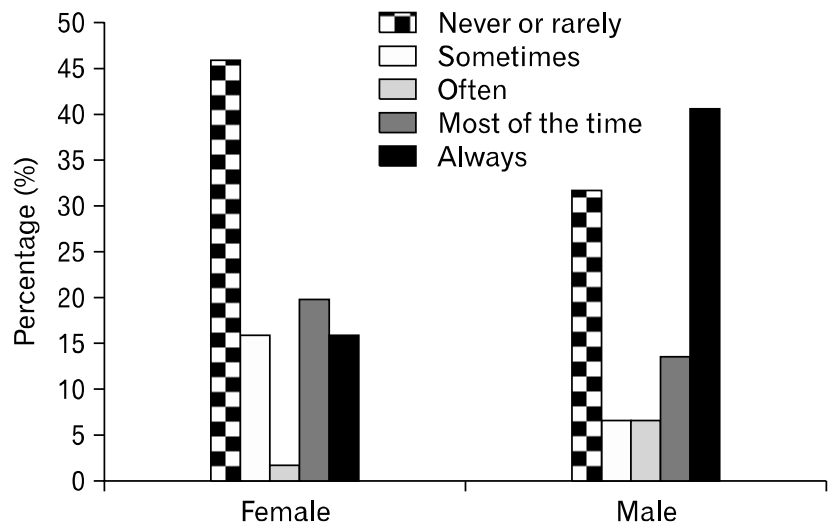

Figure 2. Distribution of different severity of more frequent bowel movements after the start of discomfort or pain in female and male irritable bowel syndrome patients $(P=0.007)$.

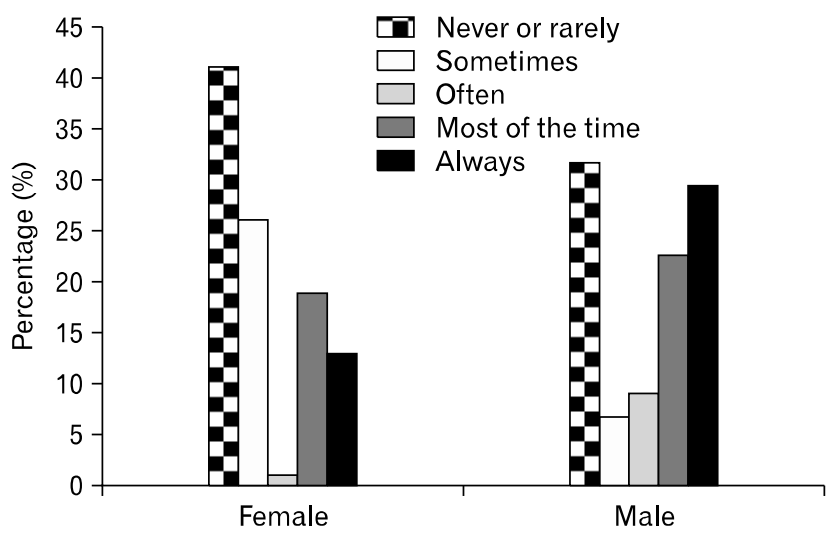

Figure 4. Distribution of the frequency of loose, mushy or watery stools within last 3 months in female and male irritable bowel syndrome patients $(P=0.002)$.

commonest subtype of IBS in male patients was IBS-D (38.6\%); while, IBS-C was the most frequent type among females (38\%). However, this difference was not statistically significant $(P=$ 0.550). As shown in Figures 2 and 3, after the start of discomfort or pain, male patients had more frequent bowel movement and more looer stool than female patients $(P=0.007$ and 0.002 , respectively). In addition, Figure 4 showed that the frequency of loose, mushy or watery stools within the last 3 months was also significantly more common in males $(2.11 \pm 1.67$ vs $1.37 \pm$ $1.50, P=0.002)$.

\section{Discussion}

Gender differences can be defined as male-female differences 
in the incidence, prevalence, mortality, burden of diseases, other adverse health conditions and the responses to those diseases and conditions. ${ }^{19}$ In this study, we report that gender is important in IBS. Although the debated finding of more women with C-IBS was confirmed, more men than women appeared to have D-IBS, according to ROME III criteria. Even though the qualitative comparison of different subtypes of IBS between male and female failed to meet the statistically significant level with the sample size of 144, the answers to the corresponding questions of ROME III IBS module were significantly different between 2 genders suggesting the higher prevalence of bowel movements and looser stool in males.

Gender differences in IBS are well established. In one of the pivotal studies in this area, Drossman et al ${ }^{20}$ noted that the ratio of men:women with IBS was as high as 2:1, although other have reported a somewhat lower ratio. ${ }^{21,22}$ However, IBS is a heterogeneous disease, with some patients suffering more with constipation symptoms and others with diarrhea. As a result of this heterogeneity, patients with IBS historically have been assigned to either one of the groups, IBS-C or IBS-D. ${ }^{23}$ To define these categorical assignments better, Rome III criteria provided a consensus-based approach in which gender was evaluated according to the presence or absence of IBS-C or IBS-D. ${ }^{24}$ In 2 studies, the gender disparity in IBS appeared more prominent among patients who had IBS-C. ${ }^{25,26}$ These studies suggest that the preponderance of women with IBS is more pronounced in the IBS-C category and that, in fact, the IBS-C category may account for all the female gender inequalities in IBS.

In addition, there is a greater prevalence of IBS in patients with other chronic pain conditions, which are more common in women, such as chronic fatigue syndrome compared with the general population, and similarly there is a greater prevalence of these conditions in patients with IBS. ${ }^{27}$

With regard to specific IBS symptoms, women with IBS are more likely to report problems with constipation while men more commonly report diarrhea. There have been some studies showing that women report significantly more constipation as compared to men. ${ }^{28}$ Hyams et al ${ }^{29}$ looked at symptoms of constipation and found that women were significantly more likely to report straining and bloating. Talley et $\mathrm{al}^{21}$ found that significantly more women than men reported to experience bloating. In another study, ${ }^{30}$ women were initially found to have significantly more constipation, but when the investigators controlled for factors such as laxative use and a feeling of incomplete evacuation, the significance disappeared. Hochstrasser and Angst ${ }^{31}$ found that significantly more men than women reported constipation.

Two studies examining gender differences in diarrhea found opposite results, with Hochstrasser and Angst, ${ }^{31}$ utilizing ROME criteria I, showing significantly more women than men having diarrhea, whereas Talley et al, ${ }^{21}$ utilizing ROME criteria I, found that, in their sample, more men reported diarrhea. Findings regarding gender differences in overall symptomology compatible with an IBS diagnosis are similarly inconsistent, with several studies finding no gender differences, ${ }^{21,29-31}$ whereas other studies $^{25,32}$ showed more women than men reporting symptoms that met the Manning criteria for the diagnosis of IBS. Most recently, published Herman et $\mathrm{al}^{33}$ assessed the association of constipation and gender in IBS, and reported that the female:male ratio significantly increased according to the severity of constipation relative to the severity of diarrhea.

Ali et $\mathrm{al}^{34}$ looked into the relationship between gender role and illness behavior in IBS and found a correlation between what were typically viewed as feminine characteristics and disease conviction in both male and female IBS patients in a tertiary care setting. Specifically, women and men who showed high scores on traits such as nurturance also showed high scores on disease conviction. One important implication of this finding is that it may be the feminine gender role, rather than being female, that is influential in affecting patients' attributions to their illness.

Another symptom which was found to have a gender-related preponderance in our IBS patients was nausea. Our results show that nausea has an approximately 2.5 -fold higher prevalence in women with IBS compared with the men. Similar findings was reported from our previous investigation based on ROME II criteria where nausea was shown to be more complained among female IBS sufferers $(13.2 \%$ vs $26.7 \%, P=0.020) .{ }^{17}$ Admittedly, Lee et $\mathrm{al}^{15}$ declared that female IBS patients more often reported nausea, alterations of taste and smell, and unpleasant sensations on the tongue. On the study of 714 ROME I positive IBS patients, nausea was twice as commonly reported by premenopausal women than by postmenopausal women, while, no differences were found between postmenopausal women and age-matched male IBS cases. Lee et $\mathrm{al}^{15}$ suggested that this prominent prevalence of nausea in premenopausal women with IBS might be related to the menstrual cycle. Mayer et a ${ }^{16}$ also believed that nausea as well as stomach and pelvic cramping pains were rated higher during menstruation in the IBS female patients.

The question of the role of gender in IBS has risen from studies suggesting an effect of the menstrual cycle on symptom severity, as it appears to emerge around the time of puberty and 
increases during the early adult years with the more recent drug studies suggesting that the $5-\mathrm{HT}_{3}$ antagonist alosetron and the partial $5-\mathrm{HT}_{4}$ agonist tegaserod are more effective in women than in men. ${ }^{2}$

The variability in reproductive hormones across the menstrual cycle as well as the decrease in ovarian function at menopause may serve as important factors influencing GI motility and visceral sensitivity. Several studies have demonstrated the impact of menstrual cycle on GI symptoms. ${ }^{35-37}$ Specifically, many women with and without IBS experience an increase in GI symptoms including abdominal pain, bloating, and intestinal gas during the late luteal and menstruation phases of the cycle. In addition, menstrual cycle phase may affect visceral sensitivity in women with IBS. $^{16}$

Although this study investigated the epidemiologic association between IBS and gender, the exact role of gender remains to be determined. Continuing exploration of the epidemiology of IBS repeatedly suggests that, in addition to functional gastrointestinal disease in general, pain-related symptoms, ${ }^{16}$ bloating and constipation are clearly more prevalent in females. Understanding the reasons for this disparity has been challenging, and a wide variety of biopsychosocial hypotheses have been explored. Comprehensive reviews of gender and IBS are widely available. Many independent factors that might potentially explain the gender disparity have been evaluated such as the differences in the sex hormones. ${ }^{38}$ Examination of abuse as a risk factor for IBS has not convincingly suggested gender disparity. No differences in health care-seeking behavior ${ }^{23}$ or psychological distress ${ }^{24}$ have been observed between male and female patients with IBS.

Generally, there are some evidences to be offered for gender-related differences in IBS such as the symptom presentation and IBS subtypes, as well as pathophysiology and treatment responses. ${ }^{39}$ These clues were further evaluated by our investigation which was shown some female prominence in the prevalence of nausea in IBS patients. Our study utilized the Rome III criteria for IBS assessment. Among the previous investigations on gender-related differences in IBS patients, few have examined this association according to the current ROME III criteria. Although the use of ROME III criteria and the appropriate sample size strengthen our findings, there are some limitations to the present study, too. The evaluations and comparisons in our study were based on the ROME criteria and modules and therefore, did not take the severity of constipation or diarrhea into account. However, there are not enough validated objective tools to measure the severity or degree of such symptoms. Another issue that could be problematic was the patient selection. Our study was a single center investigation which could be affected by the specific socio-cultural habits of the inhabitants in the region. Especially the gender issue may have had a considerable role in this case and therefore, it necessitates the performance of population- and multicenter-based studies.

In conclusion, nausea was found to be reported more by female IBS patients. Although qualitative comparison of different subtypes of IBS between two genders failed to meet the statistically significant level, the answers to the corresponding questions of ROME III IBS module were significantly different between two genders suggesting the higher prevalence of bowel movements and looser stool in males. Our findings indicate the gender-related differences in IBS which necessitates more investigations on the underlying reasons of these disparities.

\section{References}

1. Longstreth GF, Thompson WG, Chey WD, Houghton LA, Mearin F, Spiller RC. Functional bowel disorders. Gastroenterology 2006;130:1480-1491.

2. Ouyang A, Wrzos HF. Contribution of gender to pathophysiology and clinical presentation of IBS: should management be different in women? Am J Gastroenterol 2006;101(12 suppl):S602-S609.

3. Chang FY, Lu CL, Chen TS. The current prevalence of irritable bowel syndrome in Asia. J Neurogastroenterol Motil 2010;16:389400.

4. Drossman DA, Li Z, Andruzzi E, et al. U.S. householder survey of functional gastrointestinal disorders. Prevalence, sociodemography, and health impact. Dig Dis Sci 1993;38:1569-1580.

5. Unruh AM. Gender variations in clinical pain experience. Pain 1996;65:123-167.

6. Andersson HI, Ejlertsson G, Leden I, Rosenberg C. Chronic pain in a geographically defined general population: studies of differences in age, gender, social class, and pain localization. Clin J Pain 1993;9: 174-182.

7. James FR, Large RG, Bushnell JA, Wells JE. Epidemiology of pain in New Zealand. Pain 1991;44:279-283.

8. Eggen AE. The Troms $\varnothing$ Study: frequency and predicting factory of analgesic drug use in a free-living population (12-56 years). J Clin Epidemiol 1993;46:1297-1304.

9. Ektor-Anderson J, Janzon L, Sjölund B. Chronic pain and the sociodemographic environment: results from the Pain Clinic at Malmö General Hospital in Sweden. Clin J Pain 1993;9:183-188.

10. Klonoff EA, Landrine H, Brown M. Appraisal and response to pain may be a function of its bodily location. J Psychosom Res 1993;37: 661-670.

11. Lembo T, Fullerton S, Diehl D, et al. Symptom duration in patients with irritable bowel syndrome. Am J Gastroenterol 1996;91:898905.

12. Masand PS, Kaplan DS, Gupta S, et al. Major depression and irritable bowel syndrome: is there a relationship? J Clin Psychiatry 1995; 
56:363-367.

13. Talley NJ, Phillips SF, Bruce B, Twomey CK, Zinsmeister AR, Melton LJ 3rd. Relation among personality and symptoms in nonulcer dyspepsia and the irritable bowel syndrome. Gastroenterology 1990;99:327-333.

14. Walker EA, Gelfand AN, Gelfand MD, Katon WJ. Psychiatric diagnoses, sexual and physical victimization, and disability in patients with irritable bowel syndrome or inflammatory bowel disease. Psychol Med 1995;25:1257-1267.

15. Lee OY, Mayer EA, Schmulson M, Chang L, Naliboff B. Genderrelated differences in IBS symptoms. Am J Gastroenterol 2001;96: 2184-2193.

16. Mayer EA, Naliboff B, Lee O, Munakata J, Chang L. Review article: gender related differences in functional gastrointestinal disorders. Aliment Pharmacol Ther 1999;13(suppl 2):65-69.

17. Ebrahimi Daryani N, Faramarzi Garousi F, Ghofrani H, Hosseini P, Bashashati M, Hashtroudi AA. Clinical manifestations of irritable bowel syndrome in Iranian men and women: a comparative study. Govaresh 2006;11:17-21.

18. Khoshkrood-Mansoori B, Pourhoseingholi MA, Safaee A, et al. Irritable bowel syndrome: a population based study. J Gastrointestin Liver Dis 2009;18:413-418.

19. Heitkemper M, Jarrett M. Irritable bowel syndrome: does gender matter? J Psychosom Res 2008;64:583-587.

20. Drossman DA, Whitehead WE, Camilleri M. Irritable bowel syndrome: a technical review for practice guideline development. Gastroenterology 1997;112:2120-2137.

21. Talley NJ, Zinsmeister AR, Van Dyke C, Melton LJ 3rd. Epidemiology of colonic symptoms and the irritable bowel syndrome. Gastroenterology 1991;101:927-934.

22. Saito YA, Locke GR, Talley NJ, Zinsmeister AR, Fett SL, Melton LJ 3rd. A comparison of the Rome and Manning criteria for case identification in epidemiological investigations of irritable bowel syndrome. Am J Gastroenterol 2000;95:2816-2824.

23. Drossman DA, Thompson WG, Talley NJ, Funch-Jensen P, Janssens J, Whitehead WE. Identification of sub-groups of functional gastrointestinal disorders. Gastroenterol Int 1990;3:159-172.

24. Thompson WG, Longstreth GF, Drossman DA, Heaton KW, Irvine EJ, Müller-Lissner SA. Functional bowel disorders and functional abdominal pain. Gut 1999;45(suppl 2):II43-II47.

25. Talley NJ, Zinsmeister AR, Melton LJ 3rd. Irritable bowel syndrome in a community: symptom subgroups, risk factors, and health care utilization. Am J Epidemiol 1995;142:76-83.

26. Schmulson M, Lee OY, Chang L, Naliboff B, Mayer EA. Symptom differences in moderate to severe IBS patients based on predominant bowel habit. Am J Gastroenterol 1999;94:2929-2935.

27. Whitehead WE, Palsson O, Jones KR. Systematic review of the comorbidity of irritable bowel syndrome with other disorders: what are the causes and implications? Gastroenterology 2002;122:1140-1156.

28. Toner BB, Akman D. Gender role and irritable bowel syndrome: literature review and hypothesis. Am J Gastroenterol 2000;95:11-16.

29. Hyams JS, Burke G, Davis PM, Rzepski B, Andrulonis PA. Abdominal pain and irritable bowel syndrome in adolescents: a community-based study. J Pediatr 1996;129:220-226.

30. Talley NJ, O'Keefe EA, Zinsmeister AR, Melton LJ 3rd. Prevalence of gastrointestinal symptoms in the elderly: a population-based study. Gastroenterology 1992;102:895-901.

31. Hochstrasser B, Angst J. The Zurich study: XXII. Epidemiology of gastrointestinal complaints and comorbidity with anxiety and depression. Eur Arch Psychiatry Clin Neurosci 1996;246:261-272.

32. Kay L, Jørgensen T, Jensen K. The epidemiology of irritable bowel syndrome in a random population: prevalence, incidence, natural history and risk factors. J Intern Med 1994;236:23-30.

33. Herman J, Pokkunuri V, Braham L, Pimentel M. Gender distribution in irritable bowel syndrome is proportional to the severity of constipation relative to diarrhea. Gend Med 2010;7:240-246.

34. Ali A, Richardson D, Toner B. Feminine gender role and illness behavior in irritable bowel syndrome. J Gender Culture Health 1998; 3:59-65.

35. Heitkemper NM, Cain KC, Jarrett ME, Burr RL, Hertig V, Bond EF. Symptoms across the menstrual cycle in women with irritable bowelsyndrome. Am J Gastroenterol 2003;98:420-430.

36. Altman G, Cain K, Motzer S, Jarrett M, Burr R, Heitkemper M. Increased symptoms in female IBS patients with dysmenorrhea and PMS. Gastroenterol Nurs 2006;29:4-11.

37. Björnsson B, Orvar KB, Theodórs A, Kjeld M. The relationship of gastrointestinal symptoms and menstrual cycle phase in young healthy women. Laeknabladid 2006;92:677-682.

38. Makharia GK, Verma AK, Amarchand R, et al. Prevalence of irritable bowel syndrome: a community based study from Northern India. J Neurogastroenterol Motil 2011;17:82-87.

39. Jung HK. Is there true gender difference of irritable bowel syndrome in Asia? J Neurogastroenterol Motil 2011;17:206-207. 